\title{
ethic @ \\ NIETZSCHE E LA ROCHEFOUCAULD: O MORALISTA COMO PSICÓLOGO
}

\author{
NIETZSCHE AND LA ROCHEFOUCAULD: THE MORALIST AS \\ A PSYCHOLOGIST
}

\author{
JELSON ROBERTO OLIVEIRA ${ }^{1}$ \\ (PUCPR/Brasil)
}

\begin{abstract}
RESUMO
No presente artigo pretende-se analisar a influência do duque de La Rochefoucauld sobre Nietzsche, levando em conta especialmente as leituras realizadas no contexto de elaboração de Humano, demasiado humano, a partir de 1876. Para tanto, objetiva-se demonstrar como o moralista é evocado como psicólogo na perspectiva das observações psicológicas que servem a Nietzsche de crítica aos idealismos metafísicos. Inicia-se analisando a influência de La Rochefoucauld na experiência de Sorrento, que está na gênese de Humano, demasiado humano, principalmente pela presença de Paul Rée e, a seguir, examina-se a linguagem aforística como forma de expressão da filosofia do espírito livre, para então analisar como a moral é colocada em questão e apresentar três eixos de aproximação possíveis entre a teoria proposta por La Rochefoucauld e aquela utilizada por Nietzsche.
\end{abstract}

Palavras-chave: Moralistas franceses; La Rochefoucauld; Psicologia; Nietzsche; Aforismo; Espírito livre.

\begin{abstract}
This article aims to analyze the influence of the Duke of La Rochefoucauld on Nietzsche, considering especially the readings made in the context of the elaboration of Human, all too human, from 1876. The objective is to demonstrate how the moralist is evoked as a psychologist from the perspective of the psychological observations that serve to Nietzsche's criticism of metaphysical idealisms. It begins by analyzing the influence of La Rochefoucauld on the experience of Sorrento, which is in the genesis of Human, all too human, mainly due to the presence of Paul Rée, and then, it examines the aphoristic language as a way of expression the philosophy of free spirit, to then analyze how morality is put in check and present three possible axes of approximation between the theory proposed by La Rochefoucauld and that one used by Nietzsche.
\end{abstract}

Keywords: French moralists; La Rochefoucauld; Psychology; Nietzsche; Aphorism; Free spirit. 


\section{Introdução}

No aforismo 5 de Miscelânea de opiniões e sentenças, que forma parte do segundo volume de Humano, demasiado humano e que demonstra, já pelo título, a proximidade teórica e estilística de Nietzsche com os moralistas franceses, o filósofo alemão caracteriza tais "moralistas" como "examinadores do homem" (Menschenprüfer), contrapostos aos filósofos que, segundo ele, costumam se beneficiar das suas teses, embora acabem por "estragá-las". Ao contrário dos filósofos, os moralistas compreenderiam a variação temporal e geográfica daquilo que caracteriza a humanidade, evitando a generalização e a abstração próprias da filosofia (a referência aqui é Schopenhauer, para quem a ideia de vontade foi tomada de forma metafísica). Ora, os moralistas incluiriam "especialmente mas não exclusivamente, autores dos séculos XVI e XVII" (PIPPIN, 2011, p. 7), aos quais Nietzsche se refere constantemente e cuja confissão de parentesco mais evidente encontra-se em Ecce Homo: "É um número na verdade pequeno de velhos franceses que sempre retorno: creio apenas na cultura francesa e vejo como um mal entendido tudo que mais se denomina cultura na Europa, para não falar da cultura alemã" $\left(\mathrm{EH}^{2}\right.$, Por que sou tão inteligente, 3).

Nesse caso, os chamados moralistas franceses são também tratados por Nietzsche como "psicólogos", ou seja, como inquiridores das questões humanas, como aqueles capazes de praticar a observação psicológica, que seria o método adequado para alcançar a origem fisiopsicológica dos sentimentos morais. Entre os nomes antigos, Nietzsche destaca Michael Montaigne (citado 48 vezes na KSA), Pascal (98 vezes) e François de La Rochefoucauld (cujo nome aparece 29 vezes em 25 passagens $^{3}, 8$ delas em obras publicadas ${ }^{4}$ ). Esses três autores ocupam um lugar especial, mas seria necessário incluir nessa lista Nicolas Chamfort, Paul Bourget, Vauvenargue e Fontenelle. Os três primeiros, não por acaso, autores ensaístas e aforismáticos, cuja influência, pelo filtro oferecido por Paul Rée a partir de $1876^{5}$, passa a moldar o novo estilo de escrita praticado pelo próprio Nietzsche - e no qual ele se tornará grande mestre. Com eles, Nietzsche considera se aproximar da Antiguidade: sobre essa influência, Nietzsche mesmo anota em $O$ andarilho e sua sombra, 214: "ao ler Montaigne, La Rochefoucauld, La Bruyère, Fontenelle (sobretudo o Dialogue des morts), Vauvenargues, Chamfort, estamos 
mais próximos da Antiguidade do que com qualquer grupo de seis autores de outros povos". E, por isso: "para dizer num claríssimo louvor: eles seriam, tendo escrito em grego, entendidos também pelos gregos", tamanha "luminosidade e elegante precisão naqueles franceses! Até os gregos de mais fino ouvido aprovariam essa arte" (AS, 214).

Conforme assinala Robert B. Pippin (2010, p. 9), embora essa influência muitas vezes seja apontada como limitada ao período intermediário (que o autor chama de período moralista do próprio Nietzsche), ou seja, aos livros escritos entre 1876 e 1882, é certo que a tarefa desempenhada por ele como psicólogo ou, melhor ainda, a utilização da psicologia na compreensão da moralidade, alcançará uma influência bem maior e bem mais prolongada durante sua produção filosófica posterior, incluindo obras como Além de bem mal, Para a genealogia da moral e mesmo Ecce Homo. Pippin chega mesmo a afirmar que Nietzsche é melhor entendido "não como um grande metafísico alemão, ou como o último metafísico do Ocidente, ou como destruidor ou como um minador da metafísica, ou como um autor muito interessado em metafísicas ou como um novo teórico da natureza, mas sobretudo, como um grande 'moralista francês'" (2010, p. 9), algo que afinal, não se revelaria simplesmente pelas afirmações de Nietzsche, mas pelo modo como ele pratica sua própria filosofia, pelos seus problemas centrais e, sobretudo, pelo modo (método) como ele a desenvolve.

\section{La Rochefoucauld em Sorrento}

Embora Nietzsche leia os moralistas franceses desde meados de $1860^{6}$, o interesse e a importância desses autores está ligada aos seis meses passados em Sorrento, entre outubro de 1876 e maio de 1877, na companhia de seus amigos Malwida von Meysenburg, Albert Brenner e, sobretudo, Paul Rée ${ }^{7}$, cuja influência será decisiva para a formulação daquela que foi chamada de sua "escola da suspeita" $(\mathrm{HH}$, Prólogo), nascida, como Nietzsche mesmo reconhece, de uma crise: o rompimento decisivo com Wagner e com as ideias de Schopenhauer, depois da inauguração do Festival de Bayreuth no verão de 1876 . Ao estreitar os laços com o judeu Paul Rée, Nietzsche não só fazia frente ao antissemitismo wagneriano, como resgatava o interesse que mantinha pelo autor de Psychologische Beobachtungen, obra que ele tinha lido em Basel, no ano de sua publicação, em 1873. 
Os moralistas franceses são identificados, precisamente, como aqueles que oferecem uma leitura da moral a partir da análise dos sentimentos morais, contrapondo-se, de alguma forma, à perspectiva formalista de Kant em sua tentativa de fundamentar a moralidade em uma metafísica cuja base é um a priori do mundo empírico. A análise desenvolvida pelos moralistas é desenvolvida por Rée e por Nietzsche na tentativa desse distanciar tanto de Kant quanto de Schopenhauer, em benefício de uma leitura fisiopsicológica (leia-se: científica) das origens da moralidade. É essa, em última instância, a importância desses autores para Nietzsche nesse momento e é nela que se compreende a relevância e o interesse por La Rochefoucaulf, que estava entre os autores lidos nesses dias alegres e primaveris da Vila Rubinacci, quando o cheio das laranjeiras se misturava às brisas marítimas do sul da Itália ${ }^{8}$. Rée era grande admirador desse que era um dos primeiros aforistas franceses, que logo despertará o interesse de Nietzsche, que teria lido Sentenses et Maximes no trem, durante a viagem entre a Alemanha e à Itália. Não tardou para que La Rochefoucauld estivesse entre os autores preferidos de Nietzsche e ocupasse lugar especial entre os "grandes mestres da sentença psicológica" $(\mathrm{HH}, 35)$ citados por Nietzsche no segundo livro de Humano, demasiado humano, precisamente o texto no qual ele aplica o novo procedimento da chamada "filosofia histórica" $(\mathrm{HH}, 1)$ à análise da moralidade 9 . O título desse capítulo da obra publicada em 1878 em homenagem a outro francês, Voltaire, traduz tanto a influência de Rée quanto a importância de La Rochefoucauld: contribuição à história dos sentimentos morais, uma referência clara ao título do livro de Paul Rée, de 1877. La Rochefoucauld estaria entre os autores cuja leitura favoreceria "a arte da dissecação e composição psicológica na vida social de todas as classes, onde talvez se fale muito das pessoas, mas não do ser humano" $(\mathrm{HH}, 35)$. Como é próprio do seu interesse nesse momento, as coisas humanas, demasiado humanas seriam acessadas por meio da psicologia praticada, antes, pelos moralistas franceses, cujo interesse pelo humano pode ser considerado o mais rico e o mais instigante dos assuntos filosóficos. "La Rochefoucauld e seus pares em espírito e arte" teriam levado a sério esse tesouro e revela-lo por meio de uma "arte de polir sentenças" $(\mathrm{HH}, 35)$, cuja leitura exige também agora, um novo tipo de requinte.

O nome de La Rochefoucauld segue orientando a reflexão de Nietzsche no aforismo seguinte, o 36, na qual o filósofo alemão faz referência aos benefícios da observação psicológica como um meio de 
"alívio da existência", contraposto às medidas que tentam desviar o olhar daquelas coisas mais desagradáveis que formam a condição humana. Se no primeiro aforismo, Nietzsche se refere aos benefícios, nesse segundo, ele examina as pretensas desvantagens e perigos do novo método e, para isso, cita a sentença de La Rochefoucauld que diz: "aquilo que o mundo chama de virtude não é, via de regra, senão um fantasma formado por nossas paixões, ao qual damos um nome honesto para impunemente fazer o que quisermos" $(H H, 36)^{10}$. A citação serve como uma espécie de epígrafe à obra de La Rochefoucauld e foi vertida para português por Leda Tenório da Motta em uma sentença mais enxuta: "não são nossas virtudes, muitas vezes, mais que vícios disfarçados" (MS, 15). Um leitor de Nietzsche não deixa de notar, imediatamente, uma semelhança de forma e conteúdo entre os dois autores, cuja descoberta revela as coisas humanas, demasiado humanas que permanecem escondidas no subsolo da moralidade - uma tarefa, afinal, que a observação psicológica haverá de assumir, para demonstrar que as virtudes mais puras e os valores mais sagrados têm um lugar de procedência, muitas vezes a partir de coisas que eles mesmos consideram, secundariamente, como vis e desprezíveis.

La Rochefoucauld está entre os "atiradores de boa mira": "La Rochefoucauld e outros mestres franceses (aos quais recentemente se juntou um alemão, o autor das Observações psicológicas) parecem atiradores de boa mira que acertam sempre no ponto escuro - mas no escuro da natureza humana" $(\mathrm{HH}, 36)$. Note-se como Nietzsche deixa claro nesse aforismo que La Rochefoucauld e Paul Rée ocupam um mesmo espaço, ou seja, o moralista e o observador psicológico têm em comum as coisas humanas, embora ambos com o preço de sofrerem objeções porque suas "verdades" distanciam-se dos humanismos reinantes e o que eles desvelam aproxima-se daquilo que geralmente se considera como desumano ou inumano. Serão, no geral, amaldiçoados pelo senso comum, acusados de "plantar na alma humana o gosto pela diminuição e pela suspeita" (HH, 36), uma sina, afinal, que será partilhada pelo próprio Nietzsche. Conforme destaca Faber (2015, p. 207), um dos motivos do interesse de Nietzsche por La Rochefoucauld é que as Maximes são, por excelência, uma obra psicológica cuja visão do homem é "materialista, uma investigação psicológica da motivação e do comportamento", na qual não comparece nenhuma ideia metafísica, religiosa ou, mesmo, de alguma visão heroica do ser humano. Ele está entre os autores de obras que 
"contêm mais pensamentos reais do que todos os livros dos filósofos alemães reunidos" (AS, 214) e, além disso, tais pensamentos são inspiradores: "pensamentos do tipo que gera pensamentos".

Embora Nietzsche reconheça que a análise de La Rochefoucauld não foi capaz de se desprender totalmente da moralidade que ele pretende analisar (basicamente porque não colocou a própria moral em questão, como veremos adiante), tal posição não impede de notar a importância de seu pensamento, em contraposição ao modo alemão. É o que lemos, por exemplo, em Ecce Homo (O caso Wagner, 3):

O "espírito alemão" é o meu ar ruim: respiro com dificuldade na vizinhança dessa impureza in psychologicis tornada instinto, que cada palavra e cada gesto de um alemão revelam. Eles nunca passaram por um século XVII de duro exame de si mesmo, como os franceses - um La Rochefoucauld, um Descartes são cem vezes superiores em retidão aos primeiros alemães -, até hoje não tiveram um psicólogo. Mas a psicologia é quase que a medida do asseio ou desasseio de uma raça... E quando não se é sequer asseado, como alguém poderia ser profundo?" (EH, CW, 3)

Contrapondo os franceses em geral e La Rochefoucauld em particular aos alemães, Nietzsche reconhece também a sua aproximação com a psicologia, enquanto tarefa de asseio, ou seja, como "duro exame de si mesmo" e revelação do que está nas profundezas dos sentimentos orientadores de uma raça. Ao contrário dos franceses, os alemães teriam produzido apenas "falsários 'inconscientes'" e "fabricantes de véus". É nisso, precisamente, que Nietzsche, segundo ele mesmo, se distinguiria. E para fazê-lo, não tinha outro caminho a não ser aproximar-se dos franceses e seu espírito de asseio.

\section{O aforismo como filosofia do "espírito livre"}

O estilo dos moralistas franceses é analisado (e admirado) por Nietzsche tanto do ponto de vista de seu conteúdo quanto de sua forma. No primeiro caso, o filósofo alemão aprova sua "estima pela vida contemplativa" (FP 16[51], de 1876), que fazia de sua filosofia uma "arte de viver" que levava ao embelezamento e à estilização da vida (PONTON, 2007, p. 268). Uma passagem de Humano, demasiado 
humano deixa isso claro: "são talvez as vantagens de nosso tempo que trazem consigo um retrocesso e uma ocasional subestimação da vita comtemplativa. Mas é preciso reconhecer que nosso tempo é pobre em grandes moralistas; que Pascal, Epiteto, Sêneca, Plutarco ${ }^{11}$ são bem pouco lidos" (HH, 282). Com isso, os moralistas franceses (e, conforme defendemos aqui, especialmente La Rochefoucauld) são considerados como espíritos livres, cuja filosofia é uma resistência ao "trabalho e à diligência" impostas pelo "enorme aceleramento da vida" de quem vive como um "viajante que conhece terras e povos pela janela do trem" $(\mathrm{HH}, 282)$. Eles seriam, nesse caso, antimodernos par excellence.

No caso da forma, La Rochefoucauld deixa de herança para Nietzsche, na perspectiva de sua análise e da forma de apresentá-la, as técnicas aforísticas e poéticas que incluem a polêmica, o sarcasmo e os insights derivados das observações atentas da condição humana, pois seus aforismos são, na verdade, uma espécie de escavação: com eles vem à tona o quanto de humano está escondido por trás dos requintes e das máscaras usadas na vida social, principalmente aquelas que fundam a moralidade dos costumes.

Por meio do aforismo, La Rochefoucauld veicula seu pensamento de forma não sistemática, somando, mais ou menos casualmente, um conjunto de reflexões e provocações que se distanciam, aos olhos de Nietzsche, da obra ordenada de um Kant ou, principalmente, de um Schopenhauer ${ }^{12}$ - ao invés de uma verdade última, alcançada sistematicamente, várias verdades, aparecidas aleatoriamente, "kleinen unscheinbaren Wahrheiten", pequenas verdades imperceptíveis $(\mathrm{HH}, 3)$; ao invés da pompa das grandes filosofias, a simplicidade e a discrição dos temas e das fórmulas. Isso foi notado também por Donnellan: "o aforismo não é apenas apropriado como veículo para o pensamento disciplinado do 'espírito livre', mas ele também é a expressão simbólica ideal da sua [Nietzsche] aversão ao sistema" (1979, p. 311). Nisso, La Rochefoucauld, como os demais franceses, tinham sido mestres, precisamente devido à sua prática insistente: por isso, afirma Nietzsche, "hoje temos que obrigatoriamente frequentar os antigos franceses" (HH, 203). Eles alcançariam louvor mesmo entre os gregos: "uma coisa eles [os gregos] teriam que admirar e venerar, a espirituosidade francesa da expressão" (AS, 214). O autor francês, assim, serve como uma espécie de "antítese irônica" (para usar uma expressão de Ponton, 2007, p. 144) em relação à influência de Schopenhauer que Nietzsche pretende superar. 
Assim, a forma aforismática de La Rochefoucauld dá azo àquilo que Nietzsche anseia nesse tempo em relação à sua própria filosofia anti-idealista: "para ele, essa parece ter sido a única forma honesta de fazer filosofia" (FABER, 2015, p. 208). Uma filosofia cujos aforismos são como "a ponta de um iceberg do pensamento", não revelando tudo completamente e, por isso, deixando ao leitor a tarefa da decifração, convocando-o para a tarefa do pensar cuja fórmula e caminho não está totalmente descrito, o que exige do leitor um empenho que o torne quase coautor daquilo que ele lê, dado que a nisso deve acrescentar interpretações próprias que lá não estavam anteriormente e que provavelmente não estarão para um segundo leitor. O intérprete aqui é também autor; o leitor, coautor; o autor mesmo, um outro intérprete; o outro leitor, um adversário. Rompem-se as divisas, portanto, entre o artista criador, o espectador e a própria obra. Tudo se confunde em uma mesma tarefa, em busca de um pensamento mais veraz.

Yunus Tuncel (2015) destaca, entre as técnicas literárias utilizadas pelo moralista francês, o contraste, a analogia, a expressão do extraordinário, a expressão do adjacente, o movimento entre estados adjacentes e a expressão hiperbólica. No seu artigo, Tuncel analisa como esses usos também aparecem em Nietzsche. Embora cada autor o faça a seu modo próprio, é certo que o aforista emprega a linguagem de forma compacta, expressando o anseio por causar impacto e surpresa no leitor, destacando estados de humor e traços de caráter, os exageros e as comparações que buscam a persuasão retórica e uma rebelião contra as ideias canônicas, dando preferência a certo ceticismo no campo da moralidade em relação à eficácia e à confiança nas heranças gregas e cristãs. É o que faz de La Rochefoucauld alguém que conhece melhor o que é virtude (GC, 122), porque ele vê a moralidade a partir de seu próprio ceticismo.

La Rochefoucauld serve, assim, como uma espécie de indicação para algo que Nietzsche levará mais adiante, cujos aforismos são uma espécie de vaso do qual o pensamento se derrama e a linguagem é levada à tensão máxima pelo uso de antíteses e oxímoros, paralelismos e quiasmos, similaridades, repetição de palavras, sinais, jogos de palavras, analogias, surpresas e medidas de personificação. 0 aforismo, assim, aproxima-se da sentença, da máxima e do apotegma, todos tradução de uma ideia breve, captada por palavras sintéticas e eficazes, que aproximam a linguagem tanto do provérbio quanto da anedota. O seu uso coloca Nietzsche entre La Rochefoucauld e os 
demais franceses, mas também, como acentua Donnellan (1979, p. 311), entre Lichtenberg, Novalis e outros alemães. Como Sarah Kaufman escreveu, com Nietzsche o aforismo se torna "a escritura mesma da vontade de poder" (1972, p. 167). Isso porque, essa forma de escrita traduz o jogo de forças, a instabilidade e a tensão próprias daquele conceito que Nietzsche acaba por utilizar como um dos mais centrais de sua filosofia. Como tal, o aforismo tem uma carga desintegradora do pensamento. Como mostra Faber (205), "o aforismo é um gênero que remete aos tempos clássicos de Theógenes, Hipócrates e Sêneca, entre outros de seus praticantes". A lista poderia incluir ainda Plutarco, Cícero e, por que não, a própria Bíblia (especialmente o Livro dos Provérbios).

\section{A moral em questão}

Dado que La Rochefoucauld está entre os autores de "boa mira", tal habilidade é novamente elogiada por Nietzsche no aforismo 50 de Humano, demasiado humano: "La Rochefoucauld acerta no alvo quando, na passagem mais notável de seu autorretrato (impresso pela primeira vez em 1658), previne contra a compaixão todos os que possuem razão, quando aconselha a deixá-la para as pessoas do povo", tendo em conta que a compaixão "enfraquece a alma" (HH, 50). Nietzsche, portanto, associa-se a La Rochefoucauld e, com ele, opõese precisamente a Schopenhauer, embora tenha sido a partir deste último que Nietzsche entrara em contato com os moralistas franceses ${ }^{13}$. Em outras palavras, La Rochefoucauld serve como uma espécie de ferramenta de Nietzsche tanto para a formulação de sua filosofia quanto para o distanciamento da metafísica schopenhauriana da qual ele tentava se distanciar nesse momento. Se a compaixão é o centro da tese moral schopenhauriana, ela representa para La Rochefoucauld e, consequentemente, para Nietzsche, "uma espécie de perturbação mental que a infelicidade ocasiona" $(\mathrm{HH}, 50)$. Uma tal concepção serve muito bem para exemplificar o funcionamento do método de desvelamento das bases imorais da moralidade: como valor superior, a compaixão (que servia então de critério da moral) cresce num terreno patológico (psicologicamente falando), como uma dificuldade de lidar com a infelicidade, como uma doença dos nervos travestida de sacralidade.

O modo próprio de se relacionar com a moral é descrito por Nietzsche no aforismo 103 de Aurora precisamente como uma negação 
da moral, que poderia ocorrer em dupla perspectiva: primeiro, negar que os motivos morais geralmente alegados pelas pessoas sejam realmente o que as mobiliza para ação, ou seja, reconhecer que a moralidade está embasada em embustes morais; segundo, "negar que os juízos morais repousem sobre verdades" ( $A, 103)$. Essa segunda, diz Nietzsche, é a sua própria posição: denunciar que os erros é que fundam os juízos morais e que são eles que impelem às ações tal como são. Nietzsche, contudo, afirma que a primeira posição seria possível e, até mesmo, de "grande utilidade geral" que esse teria sido o "espírito de La Rochefoucauld". Enquanto o pensador francês teria, portanto, denunciado o engano que funda a moral, mostrando que as palavras que designam virtudes escondem outros sentidos, Nietzsche teria sido mais radical ainda, revelando que as ações não são apenas motivadas por embustes, mas que elas mesmas são fundadas sobre erros. Nesses termos, já em 1880, Nietzsche parece considerar que La Rochefoucauld não estava muito contente com o que vira em suas perquirições sobre as coisas humanas que se escondiam sob a moralidade. Escreve ele: "Até agora, houve glorificadores de homens e caluniadores, mas ambos do ponto de vista moral. La Rochefoucauld e os cristãos acharam feia a visão do homem: mas este é um julgamento moral e nenhum outro era conhecido!" (6[382], do outono de 1880). Na sua posição, Nietzsche declara-se precisamente "além de bem e mal" ao afirmar: "nós o consideramos como uma natureza que não é ruim nem boa e nem sempre o achamos feio onde aqueles o detestam, e nem sempre bonito, onde aqueles o glorificam".

É o que ocorre com a alquimia: Nietzsche diz negar os seus "pressupostos", não que tenha havido alquimistas e que estes tenham se deixado levar por aqueles pressupostos. É como se ele tivesse ido mais fundo, negando os pressupostos da moral (que afinal estariam pautados na diferença entre bem e mal), mesmo que ela já esteja em funcionamento no cotidiano da vida humana. O tema aparece no fragmento póstumo 23[152], do final de 1876-verão de 1877, no qual Nietzsche afirma: "Agora, a filosofia o protege da maneira de La Rochefoucauld, leva as virtudes humanas de volta a motivos menores e básicos". E complementa: "É uma verdadeira salvação aprender que não existem ações boas ou más em si mesmas, que no mesmo sentido da sentença do cristianismo, o oposto da Antiguidade pode ser estabelecido "não há pecados, mas apenas virtudes". Mas Nietzsche considera que "La Rochefoucauld parou no meio do caminho: ele negou as 'boas' qualidades do homem - ele também deveria ter negado as 
'más'"' (3[1], verão-outono de 1882). Em outras palavras, o moralista francês não teria colocado a própria moral em questão, tarefa que Nietzsche assume como sua a partir de 1882, principalmente com a importância crescente da pergunta sobre o valor em sua filosofia, que, no limite, levará da filosofia cientifica-histórico-fisio-psicológica para a genealogia propriamente dita.

O problema, portanto, de La Rochefoucauld não seriam os seus insights práticos, mas as suas pressuposições, ou seja, o fato de que ele ainda tenha se mantido devedor da crença na moral e não tenha, como fez Nietzsche em Para a Genealogia da Moral (obra que pode ser reconhecida como um desdobramento das reflexões iniciadas em Humano, demasiado humano) - fato que explicaria porque La Rochefoucauld aproximara-se do cristianismo nos escritos póstumos, algo que fora insistentemente notado por Nietzsche em obras posteriores. Em alguns fragmentos póstumos Nietzsche associa La Rochefoucauld a Pascal como alguém que teria se esforçado mas permanecera ligado às malhas da fé cristã: 7[40], primavera-verão de 1883, Nietzsche escreve: "Em La Rochefoucauld, brilha uma maneira muito nobre de pensar a sociedade daquela época: ele próprio é um idealista decepcionado que, seguindo as instruções do cristianismo, procura os nomes feios das forças motrizes da época". O mesmo tom se repete em: 25[84], primavera de 1884 (no qual Nietzsche associa La Rochefoucauld e o cristianismo à moral do rebanho); 25[178], primavera de 1884 (o La Rochefoucauld faz uma avaliação cristã das forças propulsoras da moralidade). Conforme assinala Donnellan (1979, p. 313), "a avaliação de La Rochefoucauld por parte de Nietzsche alternadamente como membro da frívola sociedade de salão (MA 37; KG IV 2 539) ou, mais frequentemente, como um moralista severo da tradição cristã, parece de fato ter sido influenciado pela visão contemporânea do autor francês", principalmente levando-se em conta que Nietzsche deve ter lido a Introdução das Maximes escrita por Sainte-Beuve, escrita em um tom crítico, destacando os seus escritos como mera "conversação moderada" (subdued conversation) - (cf. Ernst Merian-Genast, National-Zeitung, Basel, 16 de outubro de 1939 apud DONNELLAN, 1979, p. 318). Sobre a leitura de Saint-Beuve por parte de Nietzsche, Andreas Urs Sommer destaca que ela se deu por intermédio da família Overbeck, dado o seu parco domínio do francês na época: "Foi Sainte-Beuve que proveu a Nietzsche o impulso para um contato duradouro com a literatura francesa dos séculos XVII e XVIII. A partir das horas de leitura compartilhada pouco a pouco 
passou a vicejar um projeto de livro para o qual já não era Franz, e sim Ida Overbeck que se ocupava de traduzir algumas Causeries do Siècles des Lumières" (2019, p. 21). Para Donnellan (1979, p. 305), afinal, "um dos mais frutíferos insights de La Rochefoucauld teria sido a exaltação do talento infinitamente engenhoso do ser humano quando ele atribui a si mesmo a virtuosidade como resultado de motivos baixos e egoístas" (1979, p. 308).

\section{Três perspectivas de aproximação}

Maximes tiveram mais de vinte edições durante o século XVIII com muitas traduções para várias línguas europeias. Junto com as reflexões diversas, formam um corpo capaz de oferecer uma visão perspicaz e uma atinada observação psicológica dos comportamentos humanos. Trata-se, por isso, de revelar o que se esconde no subsolo, nos porões da moralidade dos costumes, uma tarefa que se traduz já na frase que serve mais ou menos de epígrafe da obra, que não é uma interrogação mas, bem ao contrário, uma afirmação: as virtudes são vícios disfarçados, na medida em que tais vícios não podem aparecer na vida pública e, por isso, são revestidos da grandiloquência moral que tenta ocultar e desviar a atenção dos interesses diversos (e nem sempre puros e dignos como se pretende) que fundaram a vida moral.

Para La Rochefoucauld (assim como para Nietzsche), no fundo, a marca central da moralidade é sempre o amor próprio e o egoísmo, um país no qual " há sempre terras por conhecer" $(M, 3)$. Além disso, as ações grandiosas e brilhantes são consideradas nada mais do que efeitos do humor e das paixões, expressando verdadeiramente o que germina no coração humano. O problema da vaidade não demora a aparecer, junto com a preguiça e a falsa clemência que são disfarçadas na forma das virtudes: ambição, inveja, vaidade ao lado da vaidade, são vergonhas não confessadas que se opõem ao altruísmo e ao autossacrifício. Nietzsche aceita essas conclusões do moralista francês, aprofundando suas anotações sobre a incongruência entre as virtudes e o que elas escondem.

O primeiro elemento a ser analisado, a título de exemplificação, na aproximação entre os dois autores, diz respeito ao papel do corpo na análise da moralidade. Em Nietzsche, isso será absolutamente relevante para a compreensão da psicologia como uma fisiopsicológica, já que os sentimentos morais e a avaliação moral da vida como um todo seria um sintoma dos eventos fisiológicos, que ocorrem, portanto, 
no corpo (entendido como "grande razão" [ZA, Dos desprezadores do corpo], ou seja, como uma organização na qual atuam os aspectos materiais e os "espirituais", sendo estes últimos produtos dos primeiros). Para La Rochefoucauld, por sua vez, a boa ou má disposição dos órgãos do corpo produzem a força ou a fraqueza do espírito, como se lê, por exemplo, no aforismo 44. Uma passagem das Reflexões diversas, mostra claramente como a origem das doenças está relacionada a sentimentos morais:

A ambição produziu as febres agudas e frenéticas; a inveja a icterícia e a insônia; é da preguiça que vêm as letargias, as paralisias e os langores; a cólera dá sufocação, ebulição do sangue e inflamação do peito; o medo dispara o coração e da síncopes; a vaidade provoca a loucura; a avareza, a tinha e a sarna; a tristeza, o escorbuto; a crueldade, a pedra; a calúnia e a falsidade das relações, a rubéola, a bexiga e a escarlatina; devemos aos ciúmes a gangrena, a peste a raiva. As desgraças imprevistas trouxeram a apoplexia; os processos a enxaqueca e a comoção cerebral; as dívidas, as febres héticas; o tédio do casamento, a febre quartã; a prostração dos amantes que não ousam se deixar, os vapores. O amor, por si só, mais males causou que todos juntos, e não queira ninguém exprimi-los; como é causa também dos maiores bens desta vida, calemo-nos antes de maldizê-lo: havemos de teme-lo e respeitá-lo $(R, 12)$.

Um segundo elemento que aproxima as estratégias filosóficas e estilísticas de La Rochefoucauld e Nietzsche, diz respeito à análise dos pressupostos psicológicos dos sentimentos morais. Nessa linha, entre os temas comuns, com grande lastro filosófico, está o tema da vaidade, em cuja riqueza interpretativa nenhum outro século fora tão rico quanto ao XVII, repercutindo na obra de Schopenhauer, Rée e também Nietzsche ${ }^{14}$. Ligado a esse, a análise do sentimento do orgulho é constante em La Rochefoucauld interpretado como tentativa que fazemos na vida social de esconder as nossas imperfeições $(M, 36)$ e como um dos pilares de atitudes simples como as admoestações: para o moralista francês, a correção de outra pessoa diante de uma falta, é menos para convencê-lo de seu erro e muito mais para revelar que esta falta não está em nós ( $M, 37)$. Além disso, para ele, "a humildade 
é muitas vezes somente ambição fingida que serve para submeter os outros, e artifício do orgulho que se rebaixa para se exaltar" $(M, 54)$

A intenção geral desse exame é mostrar que no fundo pretensamente desinteressado de todas as ações humanas há sempre um interesse próprio, em outras palavras, egoísmo. Conforme Ponton (2007, p. 94), além de insistir que um dos erros de avaliação propostos pelo cristianismo (e que, no limite, tornam a vida um peso a ser superado pela "necessidade de redenção") é a crença em ações desinteressadas, ele também mostra que o sentimento associado a essas ações (em HH, 133 a referência a La Rochefoucauld e Lichtenberg envolve a questão do "amor puro") também seria um erro. Em outras palavras, a crença em sentimentos desinteressados é absurda. Nessa passagem Nietzsche tem em mente o que leu nas Maximes: a estratégia de análise dos sentimentos morais leva a uma avaliação profunda da psicologia do indivíduo em sua vida social (lembre-se que La Rochefoucauld é um duque, vivendo uma vida aristocrata), que incluem preocupações com o emprego de qualidades medíocres, 0 papel da lisonja, da vaidade, o medo do ridículo, a preocupação com a reputação e com mérito, com a aparência e a busca de recompensas, a avareza, a preguiça, a timidez, a sinceridade, a honestidade, o fato da virtude estar fundada na vaidade, na dissimulação e na vanglória.

A terceira estratégia de La Rochefoucauld que também é levada adiante por Nietzsche diz respeito à análise dos sentimentos relacionais, ou seja, daqueles modos de atuação e motes morais nascidos da relação com as demais pessoas. Tal análise, na verdade, tenta combater a predominância dos aspectos que Nietzsche chamará de "moral do rebanho" os quais, em última instância, estavam presentes na moral da compaixão de Schopenhauer, contra o qual o filósofo alemão se volta. Tudo o que fazemos em relação aos outros guardaria um fundo de interesse: "socorremos os outros para constrangê-los a nos socorrerem em ocasião oportuna, e são os serviços que prestamos, a bem dizer, um bem que por antecipação nós fazemos" (M, 55).

O tema do amor e da amizade estão entre os mais tematizados e são analisados com o fim de revelar o quanto eles estão fundados no egoísmo e no amor próprio, sentimentos que se escondem por trás dos gostos e do prazer com os amigos. A frase de La Rochefoucauld bem poderia "nada podemos amar senão relativamente a nós e apenas seguimos nossos gostos e nosso prazer quando preferimos os amigos a nós mesmos, mas é somente graças a essa preferência que pode a 
amizade ser verdadeira e perfeita" ( $M, 81)$. A própria amizade é tida sobre o viés desse interesse próprio: "o que os homens denominam amizade é somente uma sociedade, zelo mútuo de interesses e troca de bons ofícios; é comércio, enfim, em que o amor-próprio tem sempre algo a ganhar" (M, 83). O tema da amizade, aliás, cujo interesse foi amplo precisamente nos escritos do chamado segundo período de Nietzsche, como já mostramos em trabalhos anteriores (OLIVEIRA, 2012), é um dos mais frequentes nas Maximes, geralmente associada ao zelo comum pelo interesse, ao bem-estar e à vantagem que o amigo pode trazer.

O amor, por sua vez, é tratado tanto a partir de uma análise desse sentimento em si mesmo quanto do tema da mulher e do seu papel na relação amorosa, na esteira mesmo do que pensou Schopenhauer na Metafísica do amor sexual e no capítulo Sobre as mulheres dos Parerga e Paralipomena. Nesse segundo ponto, são frequentes as referências pouco honrosas, carregadas de um tom androcêntrico e, por vezes, machista (para usar uma palavra hodierna provavelmente insuficiente para definir esse tema), que se manifestam em passagens como: "o espírito da maior parte das mulheres mais serve para thes fortalecer a loucura que a razão" ( $M, 340)$ e "menos podem as mulheres dominar a coqueteria que a paixão" $(M, 334)$. As mulheres, assim, geralmente são vistas a partir de sua "vontade de agradar" e pelo gosto dos coquetes ( $R, 15)$. O amor, afinal, é motivo de muitas doenças: "de todas as decrepitudes, a do amor é, enfim, a mais insuportável" ( $R, 9)$.

\section{Considerações finais}

Os textos de La Rochefoucauld, eram considerados na época de Nietzsche apenas uma excentricidade de salão, nada digno para qualquer estudante de filosofia sério. Nietzsche, contudo, levou a sério La Rochefoucauld e foi responsável pela renovação do interesse por sua obra no século XX, principalmente a partir da obra de 1878, Humano, demasiado Humano. Isso se dá, precisamente, em um contexto em que o próprio Nietzsche renova a sua filosofia, inaugurando uma estratégia cujos resultados serão decisivos para a formulação de seus conceitos posteriores, levando em conta que a noção de psicologia assumida e praticada a partir de 1876 possibilitará o desenvolvimento do próprio método genealógico, o qual, somado ao conceito de vontade de poder, elevará a pergunta sobre a moral 
ocidental ao patamar mais radical de uma pergunta sobre o próprio valor dessa moral.

Nessa medida, a presença e a importância de La Rochefoucauld são imprescindíveis para a compreensão dessa estratégia, não só porque Nietzsche, como demonstramos, herda dele o estilo aforismático, mas sobretudo, porque utiliza ambiguamente seu nome como instrumento para a formulação de sua própria filosofia do espírito livre, uma filosofia interessada pelas coisas humanas e cujo projeto se revelaria eficaz para a destruição da metafísica, na medida em que pretende mostrar, ao estilo larochefoucauldiano, os elementos subjacentes às suas visões idealistas. Ao contar a origem humana daquilo que passou a ganhar a dignidade das virtudes, Nietzsche acredita destituir a metafísica de seu lugar de rainha das ciências, entregar tal posto à psicologia. O caminho para isso, como vimos, passa por uma consideração dos moralistas como psicólogos, na medida em que suas observações morais são, antes, observações psicológicas. 


\section{Notas:}

1 Professor do Programa de Pós-Graduação em Filosofia da Pontifícia Universidade Católica do Paraná (PUCPR); E-mail: jelson.oliveira@pucpr.br; Orcid-iD: https://orcid.org/0000-0002-2362-0494

2 No presente artigo usaremos as siglas convencionais para a citação das obras de Nietzsche: GC (A Gaia Ciência), HH (Humano, demasiado humano); AS (O Andarilho e sua sombra); A (Aurora); EH (Ecce Homo). Para os fragmentos póstumos, citaremos o número e a página da KSA (Kritische Studienausgabe). A tradução desses fragmentos é de nossa responsabilidade.

${ }^{3}$ A primeira delas data de setembro de 1876 (18[21]).

${ }^{4}$ Quatro vezes em Humano, demasiado humano; e uma vez em Aurora, $A$ Gaia Ciência, Para a Genealogia da Moral e Ecce Homo.

5 Os moralistas franceses são lidos por Rée, por exemplo, durante a elaboração de suas Observações psicológicas. Fazio (2003, p. 24) afirma a esse respeito: "À época da elaboração das Observações psicológicas, além de Schopenhauer e Darwin, seus autores eram sobretudo Georg Christoph Lichtenberg e os moralistas franceses do seiscentos e setecentos: La Rochefoucauld, La Bruyère, Vauvenargues e Chamfort". A própria expressão que dá título ao livro de Rée e foi assumida por Nietzsche como procedimento de análise da moralidade (Psychologische Bemerkungen) é o título de uma sessão do segundo volume de Parerga und Paralipomena. Kleine philosophische Schriften, de Schopenhauer, que sustentava, como demonstra Fazio (2003, p. 50), a importância da psicologia empírica e das observações psicológicas da moralidade, cujos escritos, considerados "excelentes" nesse campo, incluem "Teofrasto, Montaigne, La Rochefoucauld, La Bruyère, Helvétius, Chamfort, Addison, Shaftesbury, Shenstone, Lichtenberg entre outros" (SCHOPENHAUER, 1983, p. 31-32). Com isso, segundo Fazio, Rée encontrara já traçado em Schopenhauer o programa que ele mesmo viria a desenvolver, inclusive com uma lista, digamos assim, bibliográfica para a pesquisa. De La Rochefoucauld, Rée teria herdado a ideia de que as virtudes são vícios mascarados e que a vaidade e o interesse pessoal estão entre os principais motores da moralidade. A crítica à tartufice moral será frequente, tanto em Rée quanto em Nietzsche. Sobre a relação do projeto de Rée com Schopenhauer, ver DEBONA (2019), cujo texto começa por destacar o uso diferenciado do termo alemão para observações entre os dois autores: Bemerkungen e Beobachtungen e aponta como essa diferenciação é necessária para uma compreensão dos projetos de análise da moralidade empreendidos pelos dois autores.

${ }^{6}$ Em 1869 Nietzsche solicitou e recebeu como presente de Natal de sua irmã uma cópia de extratos de La Rochefoucauld, La Bruyere and Vauvenargues (cf. DONNELLAN, 1979, p. 303). 
7 Em carta à mãe de Nietzsche, d. Franciska, datada de 6 de novembro de 1876, Paul Rée se refere ao grupo como o "trevo de quatro folhas de Sorrento".

${ }^{8}$ Sobre a experiência de Sorrento, ver D'IORIO (2012).

9 Vale lembrar que essa segunda sessão foi escrita em Sorrento e, por isso, está mais influenciada por Rée e por La Rochefoucauld, citado já nos primeiros aforismos; a primeira sessão da obra havia sido escrita anteriormente e fora mais tarde incorporada ao livro.

10 Em um fragmento póstumo da primavera de 1884 (5[348]), Nietzsche retoma essa ideia afirmando que "La Rochefoucauld suspeita que 'virtude' seja uma palavra agradável para quem não está mais disposto a se vingar". Em outras palavras, a virtude é uma palavra para o cansaço do homem.

11 Vale notar que em uma anotação de seus Cadernos (KGW IV/4, p. 211), essa lista inclui o próprio La Rochefoucauld. (cf. PONTON, 2007, p. 268).

12 O qual, aliás, vale lembrar, é um leitor de La Rochefoucauld.

13 Já que Schopenhauer considerava-se também ele devedor do método filosófico das observações psicológicas. Além disso, o conhecimento dos moralistas por parte de Nietzsche pode ser debitado da leitura da obra de Lange Geschichte des Materialismus (1865), que Ihe servira, ainda em Basel, como uma espécie de introdução à filosofia (DONNELLAN, 1979, p. 318).

${ }^{14}$ Sobre a ligação do tema da vaidade com o do ressentimento em Nietzsche, ver ABBEY, 1999. 


\section{Referências bibliográficas}

ABBEY, Ruth. The Roots of Ressentiment: Nietzsche on Vanity. New Nietzsche Studies, v. 3, n. 3/4, p. 47-61, 1999.

DEBONA, Vilmar. Bemerkungen ou Beobachtungen? Sobre as "observaç,ões psicológicas" de Schopenhauer e Rée. Trans/Form/Ação, Marília, v. 42, n. 1, p. 153-178, Jan./Mar., 2019.

D'IORIO, Paolo. Le voyage de Nietzsche à Sorrente. Genèse de la philosophie de l'esprit livre. Paris: CNRS Éditions, 2012.

DONNELLAN, B. Nietzsche and La Rochefoucauld. The German Quarterly, v. 52, n. 3, Maio, 1979, p. 303-318.

FABER, Marion. The Metamorphosis of the French Aphorism: La Rochefoucauld and Nietzsche. Comparative Literature Studies, v. 23, n. 3 (Fall, 1986), p. 205-217.

FAZIO, Domenico M. Paul Rée, um profilo filosofico. Bari: Palomar di Alternative s.r.I., 2003.

LA ROCHEFOUCAULD. Máximas e Reflexões. Apresentação, tradução e notas de Leda Tenório da Motta. Rio de Janeiro: Imago, 1994.

NIETZSCHE, F. Aurora. Reflexões sobre os preconceitos morais. Trad. de Paulo César de Souza. São Paulo: Cia. das Letras, 2004.

NIETZSCHE, F. A Gaia Ciência. Trad. de Paulo César de Souza. São Paulo: Cia. das Letras, 2002.

NIETZSCHE, F. Ecce Homo. Como alguém se torna o que é. Trad. notas e posfácio Paulo César de Souza. 2. ed. 3. reimp. São Paulo: Companhia das Letras, 1995.

NIETZSCHE, F. Genealogia da Moral. Um escrito polêmico. Trad. de Paulo César de Souza. São Paulo, Brasiliense, 1987.

NIETZSCHE, F. Humano, Demasiado Humano. Um livro para espíritos livres. Trad. de Paulo César de Souza. São Paulo: Cia. das Letras, 2000. (Vol. I e II). 
NIETZSCHE, F. Sämtliche Werke. Kritische Studienausgabe (KSA). Herausgegeben von Giorgio Colli und Mazzino Montinari. München/Berlin/New York: dtv/Walter de Gruyter \& Co., 1988. (15 Einzelbänden).

PONTON, Olivier. Nietzsche - Philosophie de la lègèreté. Berlin; New York: Walter de Gruyter, 2007. (Monographien und Texte zur Nietzsche-Forschung, Band 53).

OLIVEIRA, Jelson. Para uma ética da amizade em Friedrich Nietzsche. Rio de Janeiro: 7Letras, 2011.

PIPPIN, Robert B. Nietzsche, psychology, and first philosophy. University of Chicago Press, 2011.

SCHOPENHAUER, Arthur. Parerga e Paralipomena. A cura di G. Colli e M. Carpitela. V. II. Milão, 1983.

SOMMER, Andreas Urs. O que Nietzsche leu e o que não leu. Cadernos Nietzsche, São Paulo, v. 40, n. 1, p. 9-43, abril de 2019.

TUNCEL, Yunus. Nietzsche and La Rochefoucauld: The Art of Concise and Polemical Writing. The Agonist, v. IX, n. I \& II, Fall 2015-Sprinter 2016, p. 135-145.

Received/Recebido: 16/07/2020

Approved/Aprovado: 30/08/2020 